\title{
Combined economic-emission load dispatch solution using firefly algorithm and fuzzy approach
}

\author{
M.N Abdullah, N.A Abdullah, N.F Aswan, S. A. Jumaat, N. H. Radzi, Ahmad Fateh Mohamad Nor \\ Green and Sustainable Energy (GSEnergy) Focus Group, Faculty of Electrical and Electronic Engineering, \\ Universiti Tun Hussein Onn Malaysia, Malaysia
}

\begin{tabular}{l} 
Article Info \\
\hline Article history: \\
Received Jan 17, 2019 \\
Revised Apr 10, 2019 \\
Accepted May 19, 2019 \\
\hline
\end{tabular}

Keywords:

Economic-emission dispatch Firefly algorithm

Fuzzy approach

Weighted sum method

\begin{abstract}
This paper proposes Firefly Algorithm (FA) with fuzzy approach for solving combined economic-emission load dispatch (CEELD) problem in power generation. The main objective of the CEELD problem is to determine the optimal cost and emission level of power generation and fulfill the load demand and operational constraints. The CEELD problem used weighted sum method to combine two objective functions (cost and emission) into single objective. Then, the Fuzzy-based mechanism approach is integrated in FA to find the best compromise solution for both conflicting cost and emission level. The FA has been tested on IEEE 118-bus 14-unit test system for minimization both cost of power generation and emission level. The performance of FA for solving CEELD problem has been investigated in terms of optimal solution, convergence characteristics and Pareto front solution. From the comparison of the CEELD solutions, it found that FA can provide significant cost and emission reduction compared to other methods. Thus, it can be used as alternative approach for solving any optimization problems.
\end{abstract}

Copyright (ㅇ 2019 Institute of Advanced Engineering and Science. All rights reserved.

\section{Corresponding Author:}

M. N. Abdullah,

Green and Sustainable Energy (GSEnergy) Focus Group,

Faculty of Electrical and Electronic Engineering,

Universiti Tun Hussein Onn Malaysia,

Parit Raja, 86000 Batu Pahat, Johor, Malaysia.

Email: mnoor@uthm.edu.my

\section{INTRODUCTION}

Nowadays, economic-emission problem is getting considered in today's electricity market and it is very crucial to control the emission resulted. The good quality power system will bring the great satisfaction to the consumer since most of the daily routine depends on electricity. Economic Load Dispatch (ELD) has become the critical problem in electrical power generation systems. The aim of ELD is to find an optimal power so that the generation cost will minimized while satisfying load demand and all other operational constraints [1].

Operating at minimum cost can no longer be considered alone since the consumer need a clean environment [2]. The environmental aspect need to be taken into consideration when burned the fossil fuels at thermal power plant. The emission released such as nitrogen oxide (NOx), carbon dioxide (CO2), Sulphur dioxide (SO2) and etc. are hazardous to the environment. This emission has become the main cause of air pollution [3]. The US Air Act Amendment of 1990 mandates that the electric utility industry should reduce its SO2 emissions by 10million tons/year and the NOx emission by 2 million tons/year from the 1980 level in order to reduce the environmental pollution [4]. It shows that the use of fossil fuels to generate electricity need to be minimized and controlled due to environmental pollution of burning fossil fuels [5, 6-8]. 
There are many different methods have been used as a mathematical tool for optimization problems. It can be divided into two categories which are traditional and metaheuristic methods. The Metaheuristic methods are recently used for many applications since it capable to find global optimal solution for economic-emission load dispatch (EELD) problems [1, 9-19]. In this project, Firefly Algorithm (FA) is applied to investigate the optimal cost and emission, robustness and convergence characteristics of EELD problem. The FA is first introduced by Xin-She Yang in 2008 and the behavior of the algorithm is inspired by fireflies' movement [3]. Moreover, the main advantages of FA are simple concept and easy to implement since it is based on the global communication among the swarming particles [20-22].

\section{PROBLEM FORMULATION}

Sustaining load demand while minimizing emission level and total generation cost requires big challenge as a multi-objective optimization problem. The elements of the load dispatch problem that include the objective functions and operation constraints are deeply explained as follows:

\subsection{Economic Load Dispatch}

The aim of Economic load dispatch (ELD) is to reduce the total generator cost while sustaining load demand and operational constraints. The formulation of ELD problem defined as [23]:

$$
F_{C}=\sum_{i=1}^{n g} F_{i}\left(P_{i}\right)=\sum_{i=1}^{n g} a_{i}+b_{i} P_{i}+c_{i} P_{i}^{2}
$$

where, $\mathrm{Fi}(\mathrm{Pi})$ is generation cost function $(\$ / \mathrm{h})$, ai, bi, ci are the cost coefficients for the ith generator, ng is the total number of dispatchable plants and $\mathrm{Pi}$ is the power output of ith plant.

The objective function of ELD with valve point effect can be represented as the sum of a quadratic and a sinusoidal function as follows [23]:

$$
F_{C}=\sum_{i=1}^{n g} F_{i}\left(P_{i}\right)=\sum_{i=1}^{n g}\left(a_{i}+b_{i} P_{i}+c_{i} P_{i}^{2}\right)+\left|e_{i} \sin \left(f_{i}\left(P_{i}^{\min }-P_{i}\right)\right)\right|
$$

where, ei, fi are the cost coefficients for ith generator considering the valve-point effect.

\subsection{Emission Load Dispatch}

Emission load dispatch is to reduce the total stack emission of nitrogen oxide (NOx), sulphur oxide (SOx) and carbon dioxide (CO2) for the entire system. The objective function defined as [19]:

$$
F_{E}=\sum_{i=1}^{n g} E_{i}\left(P_{i}\right)=\sum_{i=1}^{n g} \alpha_{i} P_{i}^{2}+\beta_{i} P_{i}+\gamma_{i}
$$

While, the objective function of emission load dispatch considering valve-point effect can be represented as follows [19]:

$$
F_{E}=\sum_{i=1}^{n g} E_{i}\left(P_{i}\right)=\sum_{i=1}^{n g} \alpha_{i} P_{i}^{2}+\beta_{i} P_{i}+\gamma+\left(\eta \times \exp \left(\delta_{i} \times P_{i}\right)\right)
$$

where, $\mathrm{Ei}(\mathrm{Pi})$ is the total emission released in $\mathrm{kg} / \mathrm{h}, \alpha_{i}, \beta_{i}, \gamma_{i}$ are the emission coefficient of ith generating unit and $\eta, \delta_{i}$ are the emission coefficients of ith generator with valve-point effect.

\subsection{Combined Economic and Emission Load Dispatch: Weighted Sum Method}

The aim of combined economic and emission load dispatch to minimize total generator cost and emission level that produce energy in thermal power plant simultaneously. To handle this problem, the weighted sum method is used to find the set of optimal solutions between these two conflicting objectives based on weight factor (w) as follows [5]: 


$$
F=w \sum_{i=1}^{n g} F_{i}\left(P_{i}\right)+(1-w) h_{i} \sum_{i=1}^{n g} E_{i}\left(P_{i}\right)
$$

The EELD problem is expressed in a single objective form that are formulated by combining two independent objectives which are total cost and emission level. The weighting factor (w) can be any number between 0 and 1 based our references. The price penalty factor hi is the ratio between maximum cost and maximum emission level of corresponding generator in $\$ / \mathrm{kg}[4,19]$ :

$$
h_{i}=\frac{F_{C}\left(P_{i}^{\max }\right)}{F_{E}\left(P_{i}^{\max }\right)}, \mathrm{i}=1,2, \ldots, \mathrm{ng}
$$
demand [19]:

There following steps can be used to determine the price penalty factor for a particular load

Calculate the ratio between maximum generation cost and maximum emission level "hi" of each generator.

The values of "hi" must arrange in increasing value order.

Add the maximum generated power of each generator one by one starting with the smallest unit price penalty factor until $\sum P_{i}^{\max } \geq P_{D}$.

At the point, hi associated with the final unit in this process is the nearest price penalty factor equivalent for the given load.

\subsection{Problem Constraints}

There are two operational constraints will be used in this problem constraints such as equality and inequality. The power balance constraint is referred to an equality constraint which expressed the total generated power must equal the total power demand and total power losses in the system. The equality constraint is formulated as follows [24]:

$$
\sum_{i=1}^{n g} P_{i}-P_{D}-P_{L}=0
$$

where, PL is the total real power losses and PD is the total power demand.

The generating power limits is the inequality constraints based on minimum $\left(P_{i}^{\min }\right)$ and maximum $\left(P_{i}^{\max }\right)$ power output as follows:

$$
P_{i}^{\min } \leq P_{i} \leq P_{i}^{\max }
$$

The transmission network system losses are represented as function of the real power and the Bcoefficient matrix using Kron's loss formula as follows [24, 19]:

$$
P_{L}=\sum_{i=1}^{n g} \sum_{i=1}^{n g}\left(P_{i} B_{i j} P_{j}\right)+\sum_{i=1}^{n g} B_{i 0} P_{i}+B_{00}
$$

where, Bij is the loss coefficient matrix.

\section{FIREFLY ALGORITHM FOR SOLVING ECONOMIC-EMISSION LOAD DISPATCH}

The main purpose for a firefly's glow is to act as a prompt system to attract other fireflies. This algorithm is formulated by assuming three idealized rules [25]. The fireflies attractiveness of the fireflies is related to the light intensity and defined as follows [2]:

$$
\left(\beta_{r}\right)=\beta_{0} e^{-\gamma r^{m}}, \text { with } \mathrm{m} \geq 1
$$

where, ${ }^{\beta_{0}}$ is the attractiveness at $\mathrm{r}=0$ and $\mathrm{r}$ is the distance between two fireflies. 
The movement of Firefly Algorithm is defined as the following: [26]

$$
x_{i}^{t+1}=x_{i}^{t}+\beta_{r}\left(x_{j}^{t}-x_{i}^{t}\right)+\alpha_{t} \varepsilon_{i}^{t}
$$

where, $\mathrm{x}$ is the position of each fireflies, $\beta_{r}$ is the attractiveness of the ith firefly receives from the jth fireflies, ${ }^{\alpha}$ is the randomization parameter and $\varepsilon_{i}^{t}$ is the vector of random numbers drawn from Gaussian distribution on the th iteration.

This section described about the implementation steps of Firefly Algorithm for combined economic and emission problem. The effectiveness of FA will be compared with other algorithms. The steps are implemented as follows:

Step 1: Define the objective function of economic-emission dispatch problem using (1) and (3).

Step 2: Set the parameter setting of FA which are $\alpha=0.3, \beta=0.1$ and $\gamma=1$ and number of population is set to 30.

Step 3: Insert randomized with respect to maximum power generator $\left(P_{\max }\right)$ and minimum power generator $\left(P_{\min }\right)$.

Step 4" Evaluate the new solution of Firefly Algorithm with respect to objective function to consider losses. The implementation step for each objective function are:

a. For economic dispatch, (1) is used to minimize the cost of IEEE 118-bus 14-unit test system.

b. For emission, (3) is used to minimize the emission dispatch of IEEE 118-bus 14-unit test system.

c. For minimization of combined economic and emission load dispatch, (5) is used. The weighting factor are selected from 0 to 1 with steps of 0.1 .

Step 5: Rank the new solutions from maximum to minimum depends on the objective function value and store the best solution.

Step 6: The constraints in (7), (8) and (9) can be satisfied by using Modification of Infeasible Particle (MIP) approach in [27].

Step 7: Get the movement of firefly which get the optimal solution using (10) and (11).

Step 8: Store the best solution respected to the maximum iterations. Step 4 is repeat until reached maximum number iterations.

Step 9: The best solutions are stored respected to the number of iteration using Fuzzy-based Mechanism.

Step 10: End of algorithm.

\subsection{Best Compromise Solution: Fuzzy-Based Mechanism}

The best compromise solution is selected among pareto optimal set can be determined using Fuzzybased approach. Each of objective function is represented by a mechanism function $\mu_{j}$ as shown in (12) [28].

$$
\mu_{j}=\left\{\begin{array}{c}
1, F_{j} \leq F_{j}^{\min } \\
\frac{F_{j}^{\max }-F_{j}}{F_{j}^{\text {max }}-F_{j}^{\text {min }}}, F_{j}^{\text {min }} \leq F_{j} \leq F_{j}^{\text {max }} \\
0, F_{j} \geq F_{j}^{\max }
\end{array}\right.
$$

where, $F_{j}^{\min }, F_{j}^{\max }=$ minimum and maximum value of the $\mathrm{j}$-th objective function.

A normalized mechanism function need to be evaluated for every solution i-th using (13), [28].

$$
\mu_{i}=\frac{\sum_{j}^{n} \mu_{i j}}{\sum_{i=1}^{m} \sum_{j=1}^{n} \mu_{i j}}
$$

The highest value of $\mu$ is chosen as the best compromise solution.

\section{SIMULATION RESULTS}

The objective of this result is to develop Firefly Algorithm for solving CEED problem using Weighted Sum Method and Fuzzy-Based Mechanism. The simulation and analysis were conducted to identify the performance of Firefly Algorithm on IEEE 118-Bus14-unit test system with total power demand 
is $950 \mathrm{MW}$. The parameters of Firefly Algorithm take the following values for all test system which are $\alpha=0.3, \beta=0.1$ and $\gamma=1$. The maximum iteration and number of population are set to 1000 and 30 , respectively. The generator data of cost and emission ARE taken from [28].

\subsection{Minimizing Cost and Emission Individually of IEEE 118-Bus 14-Unit System}

To validate the effectiveness of the proposed FA, each cost and emission objective function is solved individually. The results obtained this test system are shown in Table 1. It highlights the minimum cost and emission are $4303.6009 \$ / \mathrm{h}$ and $25.2374 \mathrm{~kg} / \mathrm{h}$ respectively. Table 2 presents the comparison of the FA with other method. The results show that the FA has achieved significantly better results compared to MHSA.

Table 1. Optimal Cost and Emission Obtained by FA

\begin{tabular}{ccc}
\hline Generators & Minimize Cost & Minimize Emission \\
\hline $\mathrm{P}_{1}(\mathrm{MW})$ & 104.6483 & 70.8384 \\
$\mathrm{P}_{2}(\mathrm{MW})$ & 92.7271 & 50.0000 \\
$\mathrm{P}_{3}(\mathrm{MW})$ & 50.0000 & 78.0791 \\
$\mathrm{P}_{4}(\mathrm{MW})$ & 50.0000 & 88.8467 \\
$\mathrm{P}_{5}(\mathrm{MW})$ & 50.0000 & 67.7914 \\
$\mathrm{P}_{6}(\mathrm{MW})$ & 50.0000 & 50.0000 \\
$\mathrm{P}_{7}(\mathrm{MW})$ & 50.0000 & 73.4668 \\
$\mathrm{P}_{8}(\mathrm{MW})$ & 50.0000 & 72.3696 \\
$\mathrm{P}_{9}(\mathrm{MW})$ & 59.4909 & 73.7123 \\
$\mathrm{P}_{10}(\mathrm{MW})$ & 64.6067 & 90.0105 \\
$\mathrm{P}_{11}(\mathrm{MW})$ & 64.1038 & 50.0000 \\
$\mathrm{P}_{12}(\mathrm{MW})$ & 176.9597 & 72.5723 \\
$\mathrm{P}_{13}(\mathrm{MW})$ & 50.0000 & 72.3089 \\
$\mathrm{P}_{14}(\mathrm{MW})$ & 50.0000 & 50.0000 \\
Total Power $(\mathrm{MW})$ & 962.5366 & 959.9961 \\
$\mathrm{P}_{\mathrm{L}}(\mathrm{MW})$ & 12.5366 & 9.9961 \\
$\mathrm{P}_{\mathrm{D}}(\mathrm{MW})$ & 950.0000 & 950.0000 \\
Total Cost $(\$ / \mathrm{h})$ & $\mathbf{4 3 0 3 . 6 0 0 9}$ & 4547.9254 \\
Total Emission $(\mathrm{kg} / \mathrm{h})$ & 394.1541 & $\mathbf{2 5 . 2 3 7 4}$ \\
\hline
\end{tabular}

Table 2. Comparison for Minimize Cost and Emission Individually between the Methods for Test System 2

\begin{tabular}{lllll}
\hline Algorithm & \multicolumn{3}{l}{ Minimize Cost } & \multicolumn{3}{l}{ Minimize Emission } \\
\cline { 2 - 5 } & Total Cost & Total Emission $(\mathrm{kg} / \mathrm{h})$ & Total Cost & Total Emission $(\mathrm{kg} / \mathrm{h})$ \\
& $(\$ / \mathrm{h})$ & & $(\$ / \mathrm{h})$ & 27.8920 \\
MHSA [28] & 4304.9500 & 357.3390 & 4539.2280 & 25.2374 \\
Proposed FA & 4303.6009 & 394.1541 & 4547.9254 & \\
\hline
\end{tabular}

Figure 1 shows the convergence characteristics for the best result of cost and emission. It can be seen that the approximate optimal values reached at around 200 and 300 iterations for cost and emission minimization respectively. The figure proves the high-speed convergence of FA in solving EELD problem.

\subsection{Combined Economic and Emission Load Dispatch of IEEE 118-bus 14-Unit System}

The results obtained by FA for solving combined economic and emission dispatch are tabulated in Table 3 for different weight values. From the table, it clearly shows the value $\mathrm{w}=0$ is minimize the emission while value $\mathrm{w}=1$ is minimize the total generation cost.

Table 3. Pareto front Solutions

\begin{tabular}{llllll}
\hline $\mathrm{w}$ & Cost & Emission & $\mu c$ & $\mu e$ & $\mu$ \\
\hline 0.0 & 4547.9254 & 25.2374 & 0.0000 & 1.0000 & 0.0714 \\
0.1 & 4522.6029 & 26.5943 & 0.1036 & 0.9964 & 0.0786 \\
0.2 & 4495.9941 & 31.8206 & 0.2125 & 0.9824 & 0.0854 \\
0.3 & 4466.5354 & 43.5049 & 0.3331 & 0.9511 & 0.0918 \\
0.4 & 4428.8999 & 66.2426 & 0.4871 & 0.8901 & 0.0984 \\
0.5 & 4387.9832 & 103.7431 & 0.6546 & 0.7897 & 0.1032 \\
0.6 & 4352.3001 & 146.6544 & 0.8006 & 0.6747 & 0.1054 \\
0.7 & 4330.8089 & 186.7546 & 0.8885 & 0.5673 & 0.1040 \\
0.8 & 4313.6995 & 245.1099 & 0.9586 & 0.4110 & 0.0979 \\
0.9 & 4305.3779 & 282.4456 & 0.9926 & 0.3109 & 0.0932 \\
1.0 & 4303.5753 & 398.5150 & 1.0000 & 0.0000 & 0.0715 \\
\hline
\end{tabular}


Based on Figure 2, the total cost to generate electricity at thermal power plant is increased as the weighting factor is decreased from 1 to 0 . Meanwhile, for the total emission released from the generator is decreased when the weighting factor decreased. It is shown that the total cost and emission are conflicting to each other. Therefore, the fuzzy based method in section 3.1 is used to determine the best compromise solution among the solutions in Figure 2.

Therefore, the optimal power output for best compromise solution obtained by fuzzy approach is at $\mathrm{w}=0.6$. The total cost obtained for the best compromise solution is $4352.3001 \mathrm{\$} / \mathrm{h}$ whereas the total emission produced is $146.6544 \mathrm{~kg} / \mathrm{h}$ which correspond to $\mathrm{w}=0.6$. The results obtained by proposed FA has been compared with the results of other algorithms such as NGSA-II, MHSA and HAS as shown in Table 4. It is obvious that the total cost achieved by proposed FA is significantly better than NGSA-II and MHSA in terms of cost while the emission level is slightly lower than HSA.

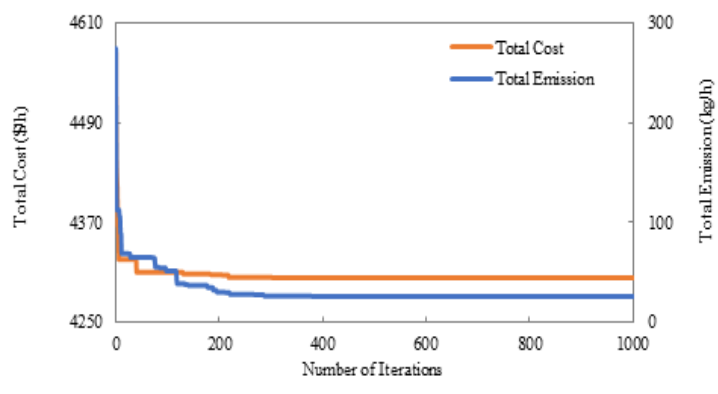

Figure 1. Convergence Characteristics of FA for minimizing Cost and Emission Individually

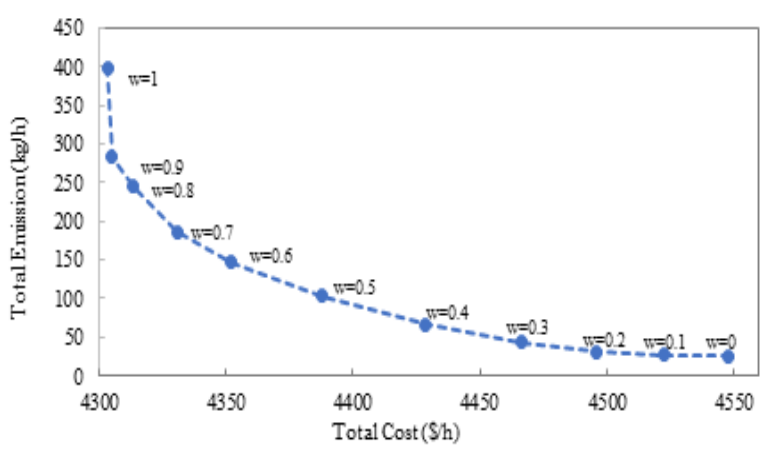

Figure 2. Pareto Front Obtained by FA with WSM

Table 4. Comparison of the Best Compromise Solutions Obtained by Different Methods

\begin{tabular}{ccccc}
\hline Algorithm & NGSA-II [29] & MHSA [29] & HSA [29] & Proposed FA \\
\hline $\mathrm{P}_{1}(\mathrm{MW})$ & 69.4618 & 79.3683 & 99.2872 & 98.9649 \\
$\mathrm{P}_{2}(\mathrm{MW})$ & 65.9624 & 62.1868 & 68.1241 & 64.1944 \\
$\mathrm{P}_{3}(\mathrm{MW})$ & 51.9713 & 50.0000 & 63.5609 & 50.0000 \\
$\mathrm{P}_{4}(\mathrm{MW})$ & 72.3437 & 61.1287 & 62.0231 & 67.3355 \\
$\mathrm{P}_{5}(\mathrm{MW})$ & 73.6853 & 78.6284 & 56.3413 & 63.5035 \\
$\mathrm{P}_{6}(\mathrm{MW})$ & 70.3004 & 51.5320 & 50.0000 & 50.0000 \\
$\mathrm{P}_{7}(\mathrm{MW})$ & 67.5641 & 67.3322 & 50.0000 & 50.0000 \\
$\mathrm{P}_{8}(\mathrm{MW})$ & 69.5526 & 50.0000 & 50.0000 & 50.0000 \\
$\mathrm{P}_{9}(\mathrm{MW})$ & 69.4421 & 79.3041 & 82.4229 & 85.1549 \\
$\mathrm{P}_{10}(\mathrm{MW})$ & 81.1416 & 93.6602 & 100.2080 & 99.0745 \\
$\mathrm{P}_{11}(\mathrm{MW})$ & 71.3414 & 68.3105 & 51.5145 & 58.2738 \\
$\mathrm{P}_{12}(\mathrm{MW})$ & 70.7760 & 96.0040 & 126.6166 & 123.4539 \\
$\mathrm{P}_{13}(\mathrm{MW})$ & 69.9194 & 68.9558 & 50.0000 & 50.0000 \\
$\mathrm{P}_{14}(\mathrm{MW})$ & 68.5146 & 53.2431 & 50.0000 & 50.0000 \\
$\mathrm{P}_{\mathrm{D}}(\mathrm{MW})$ & 900.0000 & 900.0000 & 900.0000 & 900.0000 \\
Total Cost $(\$ / \mathrm{h})$ & 4534.3995 & 4432.298 & 4326.4785 & 4352.3001 \\
Total Emission $(\mathrm{kg} / \mathrm{h})$ & 122.5034 & 100.708 & 153.7821 & 146.6544 \\
\hline
\end{tabular}

\section{CONCLUSION}

In this paper, the performance of Firefly Algorithm with fuzzy approach has been investigated to optimize the total generation cost and emission level in power dispatch. The proposed method used weighted sum method to combined both objective function (cost and emission level) and generate the set of possible solution based on various weighted values. From this solution, fuzzy mechanism is utilized to determine the best compromise solution for minimizing cost and emission of power generation simultaneously. The effectiveness of proposed algorithm has been tested on IEEE 118 nus with 14-unit system by using MATLAB software. From the simulation results, it highlights the effectiveness of proposed method in terms of optimal cost and emission, convergence characteristics, Pareto front solution and comparison of the best compromise solution. It found that FA affirms its good performances to obtain better optimal cost and emission for CEELD problems. Therefore, it can be concluded that FA confirms the effective high-quality solution for solving CEELD problem and can be used for solving any single and multi-objective problems. 


\section{ACKNOWLEDGEMENTS}

The authors would like to thank the Ministry of Education Malaysia for supporting this research under Fundamental Research Grant Scheme Vot No. K107 and partially sponsored by Universiti Tun Hussein Onn Malaysia.

\section{REFERENCES}

[1] F. P. Mahdi and P. Vasant, "Quantum Particle Swarm Optimization for Multiobjective Combined Economic Emission Dispatch Problem Using Cubic Criterion Function,” 2017.

[2] N. S. N. Abedinia, O;Amjady, "Multi-objective Environmental/Economic Dispatch Using Firefly Technique," 2012.

[3] A. Shahrim, "Economic and Emission Load Dispatch of Power Generation using Firefly Algorithm," Universiti Tun Hussein Onn Malaysia, 2017.

[4] U. Güvenç, Y. Sönmez, S. Duman, and N. Yörükeren, "Sharif University of Technology Combined economic and emission dispatch solution using gravitational search algorithm," Sci. Iran., vol. 19, no. 6, pp. 1754-1762, 2012.

[5] J. W. Fahad Parvez Mahdia, Pandian Vasanta,*, Vish Kallimanib and M. A.-A.-W. Patrick Yeoh Siew Faib, “A holistic review on optimization strategies for combined economic emission dispatch problem," Renew. Sustain. Energy Rev., Jul. 2017.

[6] C. Shilaja and K. Ravi, "Optimization of emission/economic dispatch using euclidean affine flower pollination algorithm (eFPA) and binary FPA (BFPA) in solar photo voltaic generation," Renew. Energy, vol. 107, pp. 550566, 2017.

[7] T. Apostolopoulos and A. Vlachos, "Application of the Firefly Algorithm for Solving the Economic Emissions Load Dispatch Problem," Int. J. Comb., vol. 2011, pp. 1-23, 2011.

[8] N. A. Khan, A. B. Awan, A. Mahmood, S. Razzaq, A. Zafar, and G. A. S. Sidhu, "Combined emission economic dispatch of power system including solar photo voltaic generation,” Energy Convers. Manag., vol. 92, pp. 82-91, 2015.

[9] H. Liang, Y. Liu, F. Li, and Y. Shen, "A multiobjective hybrid bat algorithm for combined economic/emission dispatch," Int. J. Electr. Power Energy Syst., vol. 101, no. November 2017, pp. 103-115, 2018.

[10] S. Bhongade, "An Optimal Solution for Combined Economic and Emission Dispatch problem using Artificial Bee Department of Electrical Engineering," 2016.

[11] A. Ghasemi, M. Gheydi, M. J. Golkar, and M. Eslami, "Modeling of Wind/Environment/Economic Dispatch in power system and solving via an online learning meta-heuristic method," Appl. Soft Comput., vol. 43, pp. 454-468, 2016.

[12] A. Aljanad, A. Mohamed, H. Shareef, and T. Khatib, "A novel method for optimal placement of vehicle-to-grid charging stations in distribution power system using a quantum binary lightning search algorithm," Sustain. Cities Soc., vol. 38, no. August 2017, pp. 174-183, 2018.

[13] M. Kheshti, X. Kang, J. Li, P. Regulski, and V. Terzija, "Lightning flash algorithm for solving non-convex combined emission economic dispatch with generator constraints," IET Gener. Transm. Distrib., vol. 12, no. 1, pp. 104-116, 2018.

[14] F. P. Mahdi, P. Vasant, V. Kallimani, J. Watada, P. Y. S. Fai, and M. Abdullah-Al-Wadud, "A holistic review on optimization strategies for combined economic emission dispatch problem," Renew. Sustain. Energy Rev., vol. 81, no. June 2017, pp. 3006-3020, 2018.

[15] J. Zhou et al., "A multi-objective multi-population ant colony optimization for economic emission dispatch considering power system security," Appl. Math. Model., vol. 45, pp. 684-704, 2017.

[16] H. Ma, Z. Yang, P. You, and M. Fei, "Multi-objective biogeography-based optimization for dynamic economic emission load dispatch considering plug-in electric vehicles charging," Energy, vol. 135, 2017.

[17] L. Jebaraj, C. Venkatesan, I. Soubache, and C. C. A. Rajan, "Application of differential evolution algorithm in static and dynamic economic or emission dispatch problem: A review," Renew. Sustain. Energy Rev., 2017.

[18] A. Y. Abdelaziz, E. S. Ali, and S. M. Abd Elazim, "Flower pollination algorithm to solve combined economic and emission dispatch problems,” Eng. Sci. Technol. an Int. J., vol. 19, no. 2, pp. 980-990, 2016.

[19] A. Y. Y. Abdelaziz, E. S. S. Ali, and S. M. M. Abd Elazim, "Combined economic and emission dispatch solution using Flower Pollination Algorithm,” Int. J. Electr. Power Energy Syst., vol. 80, pp. 264-274, 2016.

[20] Dinakara Prasad Reddy P; J N Chandra Sekhar, "Application of Firefly Algorithm for Combined Economic Load and Emission Dispatch," vol. 2, no. 8, 2014.

[21] T. A. Nugroho et al., "Coordination of blade pitch controller and battery energy storage using firefly algorithm for frequency stabilization in wind power systems, " TELKOMNIKA (Telecommunication, Computing, Electronics and Control). vol. 17, no. 2, pp. 1014-1022, 2019.

[22] M. Sababha, M. Zohdy, and M. Kafafy, "Robust pole placement using firefly algorithm," International Journal of Electrical and Computer Engineering (IJECE). vol. 9, no. 2, pp. 1058-1066, 2019.

[23] B. R. Adarsh, T. Raghunathan, T. Jayabarathi, and X. Yang, "Economic dispatch using chaotic bat algorithm," Energy, vol. 96, pp. 666-675, 2016.

[24] I. A. I. A. Farhat, Student Member, IEEE, and M. E. El-Hawary, Fellow, "Bacterial foraging algorithm for optimum economic-emission dispatch," pp. 182-186, 2011.

[25] R. Ravi, G; Velusami, S; Arul, "Chaotic firefly algorithm to solve economic load dispatch problems," pp. 
458-464, 2013.

[26] T. Shindo, J. Xiao, T. Kurihara, and K. Morita, “Analysis of the Dynamic Characteristics of Firefly Algorithm," no. 4, 2015.

[27] M. N. Abdullah, R. Tawai, and M. F. Yousof, "Comparison of Constraints Handling Methods for Economic Load Dispatch Problem using Particle Swarm Optimization Algorithm," Int. J. Adv. Sci. Eng. Inf. Technol., vol. 7, no. 4, pp. 1322-1327, 2017.

[28] M. Modiri-Delshad and N. A. Rahim, "Multi-objective backtracking search algorithm for economic emission dispatch problem," Appl. Soft Comput. J., vol. 40, pp. 479-494, 2016.

[29] B. Jeddi and V. Vahidinasab, "A Modified Harmony Search Method for Environmental/Economic Load Dispatch of Real-world Power Systems," Energy Convers. Manag., vol. 78, pp. 661-675, 2014.

\section{BIOGRAPHIES OF AUTHORS}

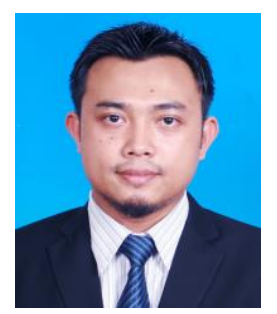

Mohd Noor Abdullah received his B.Eng. (Hons) in Electrical Engineering and M. Eng. in Electrical Engineering (Power System) from Universiti Teknologi Malaysia (UTM) in 2008 and 2010 respectively. He also received a Ph.D degree in Electrical Engineering from University of Malaya (UM) in 2014. He has been with Universiti Tun Hussein Onn Malaysia (UTHM) from 2008 to 2014 as a tutor. He is currently as a Lecturer in Department of Electrical Power Engineering, Faculty of Electrical and Electronic Engineering (FKEE), Universiti Tun Hussein Onn Malaysia (UTHM). He also appointed as a head of Green and Sustainable Energy (GSEnergy) Focus Group in FKEE, UTHM. He was a member of Board of Engineer Malaysia and IEEE. His research interests include electric power dispatch, distributed generation, renewable energy and meta-heuristic optimization techniques.

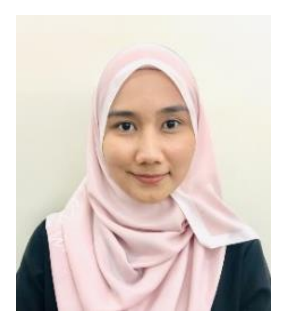

Nur Asyikin Binti Abdullah was born in January 8, 1995, in Kedah, Malaysia. She went to SMK Baling, Kedah, Malaysia for her secondary school. Before that happened, she was a primary student at SK Tuanku Abdul Rahman Putra. In early 2013, she continued her study at Kedah Matriculation College. She received her Bachelor of Electrical Engineering with Honours from Universiti Tun Hussein Onn Malaysia (UTHM) in 2018.

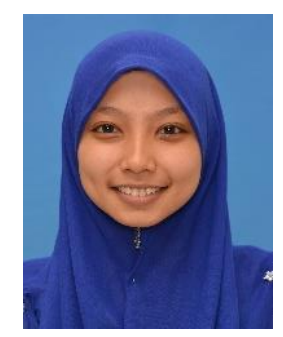

Nadia Farisha binti Aswan received the bachelor's degree in electrical engineering from Universiti Tun Hussein Onn Malaysia, Johor, Malaysia in 2017, where she is pursuing the master degree in electrical engineering. Her research interest include power dispatch, renewable energy sources and optimization algorithms.

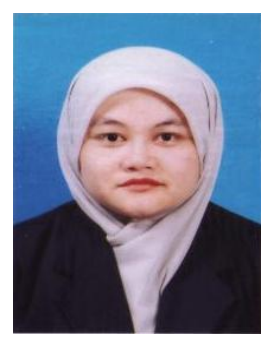

Siti Amely Jumaat was born in Johor, Malaysia on March 12, 1979. She graduated from the Institut Tun Hussein Onn (ITTHO-UTM) with honours degree in BSc. Electrical Eng. in 2001, MEng. (Power), UTM in 2003, and PhD in Electrical Eng at UiTM, Malaysia in 2015. Her research interests include power system and optimization techniques, FACTS devices, Artificial Intelligent techniques and renewable energy system. She is also a member of BEM, IEM, IEEE, and IEEE Power Engineering Society (PES) 2008.

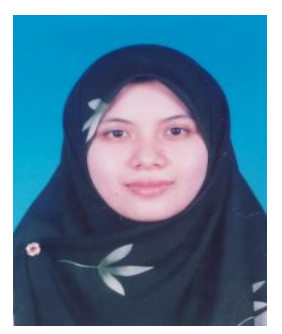

N. H. Radzi received her B.Eng. and M.Eng in Electrical Engineering (Power) from Universiti Teknologi Malaysia (UTM) in 2005 and 2009 respectively, and Ph.D from The University of Queensland, Brisbane, Australia in 2012. Currently, she is a senior lecturer in the Faculty of Electrical \& Electronic Engineering at Universiti Tun Hussein Onn Malaysia (UTHM). Her research interests include transmission pricing, power system economics, energy management and renewable 
Ahmad Fateh Mohamad Nor received Bachelor of Electrical Engineering, Master of Electrical Engineering and Ph.D. in Electrical Engineering (Power) in 2011, 2013 and 2017, respectively from Universiti Teknikal Malaysia Melaka (UTeM). Currently he is a lecturer at the Department of Electrical Power Engineering, Faculty of Electrical and Electronic Engineering, Universiti Tun Hussein Onn Malaysia. His area of research interests includes electrical power engineering, voltage instability analysis, solar electricity, artificial neural network (ANN) and adaptive neurofuzzy inference system (ANFIS). He is registered as Graduate Engineer with the Board of Engineers Malaysia (BEM). 